\title{
Jaundice as a first clinical sign of necrotizing fasciitis, caused by monomicrobial Staphylococcus aureus
}

Received: 22 October 2003 / Accepted: 18 December 2003 / Published online: 7 July 2004

(C) Springer-Verlag 2004

\begin{abstract}
Necrotizing fasciitis is a life-threatening infection, mostly caused by a mixture of gram-negative, grampositive and anaerobic organisms, frequently including haemolytic streptococci. This polyculture of bacteria demands early diagnosis and aggressive treatment to diminish the high morbidity and mortality rates. We report a young, healthy patient with acute necrotizing fasciitis with jaundice as a first clinical sign, caused by a monomicrobial Staphylococcus aureus. This type of necrotizing fasciitis is rare but can be fulminant, early diagnosis and prompt initiation of therapy are essential.
\end{abstract}

Keywords Necrotizing fasciitis - Staphylococcus aureus . Infection · Jaundice

\section{Introduction}

Necrotizing fasciitis is a rare, rapidly progressing, lifethreatening necrotizing soft tissue infection, involving subcutaneous tissue and fascia, which requires wide surgical debridement, long-term intravenous antibiotics, treatment of multi-systemic dysfunction and reconstruction [16]. Usually, necrotizing fasciitis is a synergistic polymicrobial infection that occurs in patients with coexisting factors such as diabetes, vascular disease, alcoholism, intravenous drug abuse or other causes for altered immune function $[4,9,13]$. We report on a monomicrobial variant of necrotizing fasciitis, which first presented as jaundice, affecting an otherwise healthy man. The causative bacterium was Staphylococcus aureus. The aim of this paper is to stress the virulence of this rare entity, monomicrobial Staphylococcus aureus-induced necrotizing fasciitis, and the importance of early diagnosis and aggressive treatment.

W. De Kerpel $(\bullet) \cdot$ P. Roelandt $\cdot$ M. Depoorter

Department of Plastic, Reconstructive and Aesthetic Surgery, AZ St Jan AV,

Ruddershove 10, 8000 Brugge, Belgium

e-mail: wimdekerpel@yahoo.com

Tel.: +32-50-452360

\begin{abstract}
Case report
History and clinical investigation

A 37-year-old male with no previous history, no systemic disease and right shoulder pain was admitted to our hospital on day 9. On day 1 he transported logs of wood on his right shoulder, and on days 2 and 3 he felt some stiffness in this shoulder. On day 4 he woke up in extreme pain and went to the A\&E department of the hospital. An X-ray of the right shoulder was normal and he was prescribed several pain-killers (Diclofenac, Ibuprofen, Dihydrocodeine). On day 7 , jaundice appeared, in combination with pyrexia and rigors. He was told by his general practitioner to stop the Diclofenac. On day 9, the jaundice became worse and he also noticed erythema on his right shoulder and both anterior thighs. On day 9 , he was admitted. On admission, he was generally very unwell, jaundiced, apyrexial, tachycardic and normotensive. Clinical investigation revealed erythema, swelling and limitation of movements of the right shoulder and both anterior thighs. On the rightanterior thigh, there was some induration. Palpation and percussion of the abdomen was painless.
\end{abstract}

\section{Technical investigations}

These consisted of routine biochemistry, ultrasound of the abdomen and an X-ray of the right shoulder. The blood results on admission showed anaemia, increased leucocytosis and CRP, acute renal failure, low albumin and a very high bilirubin, in comparison with the borderline-normal other liver function tests (Tables 1,2). Ultrasound of the abdomen showed no abnormalities, but an X-ray of the right shoulder showed a loss of cortex of the lateral margin of the acromioclavicular (AC) joint.

Table 1 Blood results on admission

\begin{tabular}{lclc}
\hline Parameter & Admission & & Reference \\
\hline Haemoglobin & 9.1 & $\mathrm{~g} / \mathrm{dl}$ & $13-18$ \\
WBC & 23.74 & $10^{9} / 1$ & $4.1-11$ \\
CRP & 392 & $\mathrm{mg} / \mathrm{l}$ & $<5$ \\
Sodium & 129 & $\mathrm{mmol} / \mathrm{l}$ & $132-146$ \\
Potassium & 3.9 & $\mathrm{mmol} / \mathrm{l}$ & $3.3-5.4$ \\
Urea & 32.9 & $\mathrm{mmol} / \mathrm{l}$ & $4.1-7$ \\
Creatinine & 555 & $\mathrm{mmol} / \mathrm{l}$ & $40-100$ \\
Total alkaline phospha- & 290 & $\mathrm{IU} / \mathrm{l}$ & $9.1-40$ \\
tase & 26 & $\mathrm{U} / \mathrm{l}$ & $40-129$ \\
ALT & 41 & $\mathrm{U} / 1$ & $8.1-61$ \\
Gamma GT & 181 & $\mathrm{umol} / \mathrm{l}$ & $<17$ \\
Total bilirubin & 11 & $\mathrm{~g} / \mathrm{l}$ & $35-55$ \\
Albumin & & &
\end{tabular}


Table 2 Major causes of acute renal failure

\begin{tabular}{lll}
\hline Pre-renal & Post-renal & Renal \\
\hline Fluid and electrolyte depletion & Prostatism & Acute tubular injury \\
Haemorrhage & Bladder tumour & Acute glomerulonephritis \\
Septicaemia & Pelvic tumour & Disseminated intravascular coagulopathy \\
Cardiac failure & Retroperitoneal tumour & Arterial/Venous obstruction \\
Liver failure & Calculi & Acute tubulointerstitial nephritis \\
Heatstroke & & Intra-renal precipitation \\
Burns & & \\
\hline
\end{tabular}

From Harrison's Principles of Internal Medicine (2001), p 1542

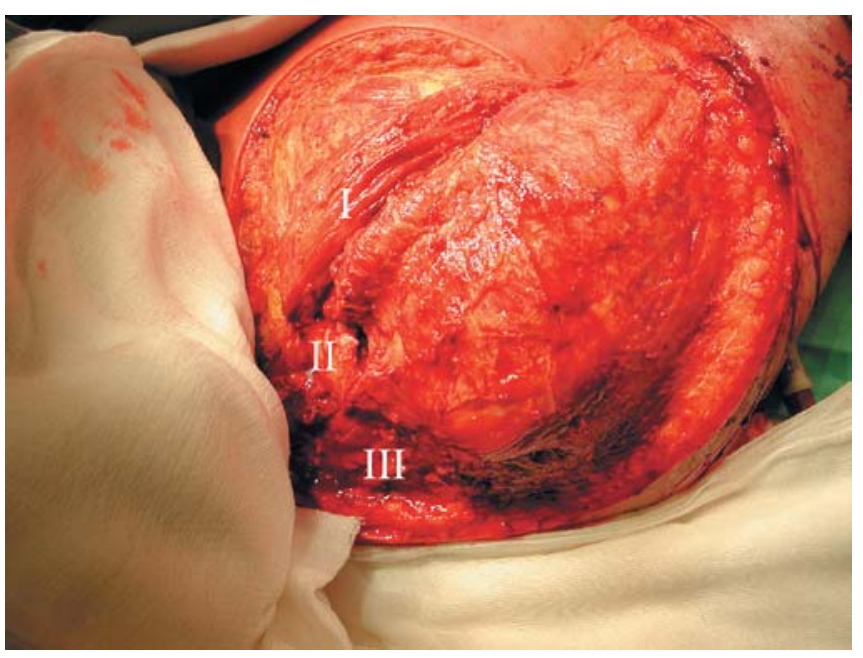

Fig. 1 Preoperative view of right shoulder. I, Deltoid muscle; II, Lateral end of clavicle; III, Trapezius muscle

\section{Diagnosis}

At this stage, it seemed most likely that necrotizing fasciitis was responsible for the acute renal failure, the jaundice and the multisystemic septic illness.

\section{Treatment}

Management was divided into early and late. Early management consisted of immediate resuscitation, intravenous broad spectrum antibiotics (penicillin, clindamycin and ciprofloxacin) and extensive debridement $1 \mathrm{~h}$ post diagnosis. Debridement of the right shoulder and both anterior thighs was performed and samples of pus, muscle and bone were taken and sent for microbiological and histopathological analysis. These samples revealed a necrotizing fasciitis, suppurative myositis of the deltoid and trapezius muscles and osteomyelitis of the lateral margin of the clavicle caused by a monomicrobial Staphylococcus aureus. His shoulder joint was free of infection. Both anterior thighs also had necrotizing fasciitis up to the intermuscular septum on the right side (Figs. 1, 2). Histopathology revealed extensive necrosis of the debrided fascia and vascular thrombosis of the dermal vessels.

The patient remained in the intensive care unit for 3 days and underwent haemofiltration on two occasions. Late management consisted of a second debridement $48 \mathrm{~h}$ after diagnosis and late reconstruction with split-skin grafting 10 days after diagnosis. The patient left the hospital 15 days after diagnosis in good health. Six months later, the patient was reviewed in our clinic; all wounds had healed nicely and he was discharged from further follow up (Fig. 3).

\section{Discussion}

Necrotizing fasciitis, first described by Ambroise Paré [6] in the fifteenth century, became a hot topic in 1994 due to

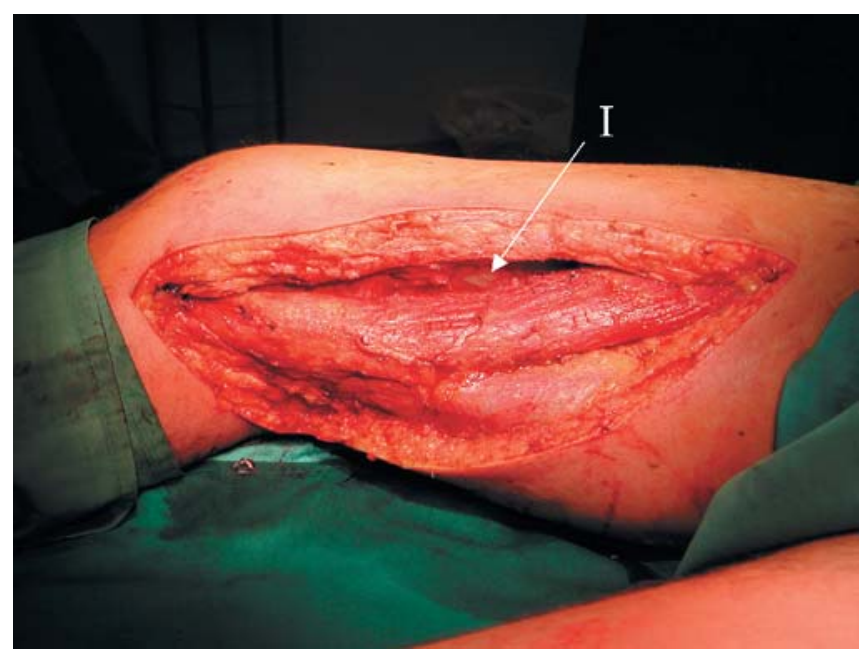

Fig. 2 Preoperative view of right thigh. $I$, intermuscular septum

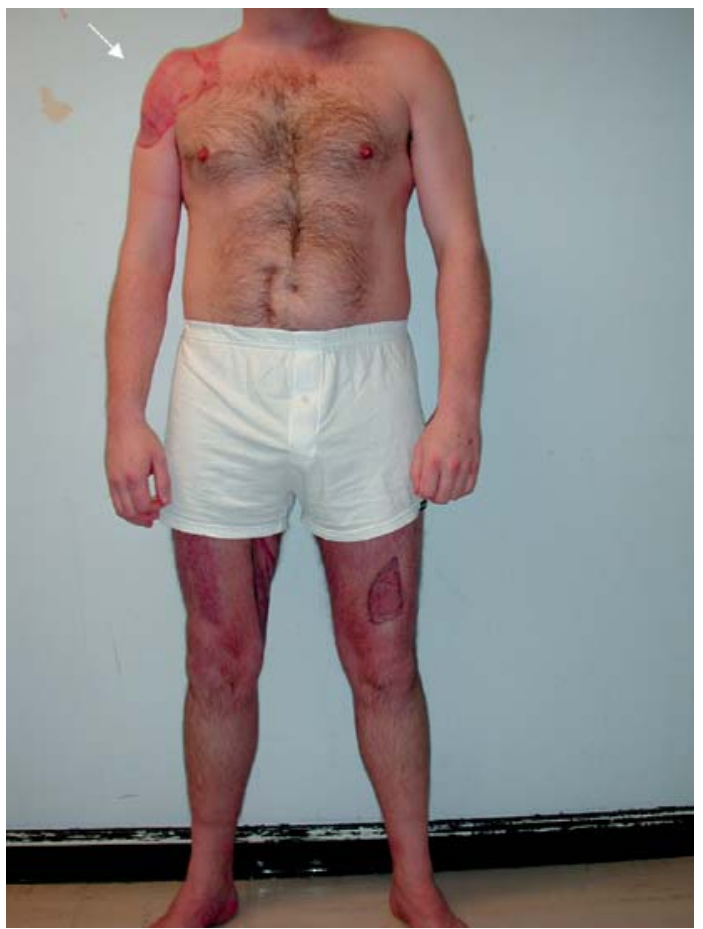

Fig. 3 Postoperative month 6

an article in the New Scientist, describing it as a flesh-eating bacterium $[8,12]$. It is a rare, rapidly progressing, lifethreatening necrotizing soft tissue infection, involving skin, subcutaneous tissue and fascia, which need wide surgical 
debridement, long-term intravenous antibiotics, treatment of multi-systemic dysfunction and reconstruction [16].

In our case, necrotizing fasciitis was induced by a splinter of wood penetrating the palm of his right hand. It has been described in literature that a remote puncture entry port may cause monomicrobial Staphylococcus aureus necrotizing fasciitis [11]. Most symptoms of necrotizing fasciitis caused by Staphylococcus aureus, are induced by the secretion of haemolysins, of which $\alpha$-toxin is the most important. This $\alpha$-toxin stimulates the endothelial cells to produce pro-inflammatory proteins such as interleukins (IL-6, IL-8), prostaglandins ( $\left.\mathrm{PGE}_{2}, \mathrm{PGI}_{2}\right)$, thromboxane $\left(\mathrm{TXA}_{2}\right)$ and growth factors (granulocyte colony stimulating factor, G-CSF) [2]. In our case, the symptoms remained subacute in the beginning, due to the intake of non-steroidal anti-inflammatory drugs from day 4 until day 9. These drugs diminish the levels of the previously mentioned pro-inflammatory proteins, especially prostaglandins and thromboxane, by inhibition of cyclooxygenase [1]. On admission, the necrotizing fasciitis was already acutely spreading and therefore, we performed two wide debridements.

Multi-systemic dysfunction in a monomicrobial Staphylococcus aureus necrotizing fasciitis is also mainly caused by the previous mentioned $\alpha$-toxin. Apart from its pro-inflammatory character, $\alpha$-toxin also has a direct cytotoxic action. High doses of $\alpha$-toxins will form a transmembranous hexamer with a central pore, causing unlimited calcium influx resulting in cell lysis [2].

In our patient two expressions of multi-systemic dysfunction were detected, acute renal failure and jaundice. The latter is caused by the effect of $\alpha$-toxins on the erythrocytes, causing intravascular haemolysins and resulting in unconjugated hyperbilirubinaemia and anaemia [2]. This life-threatening infection tends to be caused by a mixture of gram-negative, gram-positive and anaerobic organisms. Frequently isolated organisms include haemolytic streptococci, haemolytic-positive staphylococci, coagulase-positive staphylococci, Proteus mirabilis, Clostridium perfringens, Bacteroides fragilis, haemolytic Pseudomonas aeruginosa and Klebsiella [3, 5, $9,13]$. The polyculture of bacteria often seen may create bacterial synergism, causing increased virulence [14, 15]. Therefore, management with intravenous antibiotics should always consist of triple therapy with penicillin, clindamycin and quinolones to cover all possible organisms. In this case, we were dealing with a monomicrobial Staphylococcus aureus necrotizing fasciitis, which only occurs in $14 \%$ of patients with necrotizing fasciitis [10].

Although necrotizing fasciitis can be caused by a monobacterial Staphylococcus aureus, triple intravenous antibiotic therapy should be initiated as soon as possible because of high mortality rates in the case of delay of diagnosis and treatment [3]. Intravenous broad-spectrum antibiotic therapy and wide surgical debridement are the first steps in the treatment of necrotizing fasciitis. Apparently salicylic acid was recently found to be of complementary use in the treatment of Staphylococcus aureus-induced necrotizing fasciitis by lowering the levels of $\alpha$-toxin [7].
Necrotizing fasciitis caused by monomicrobial Staphylococcus aureus is rare but can be fulminant. In this case, the patient suffered from a necrotizing fasciitis of the right shoulder, associated with suppurative myositis of right deltoid and trapezius muscle, osteomyelitis of lateral border of the AC joint of his right shoulder and hematogenous spread with multi-systemic dysfunction. Because of the high mortality rates, early diagnosis and early initiation of therapy are essential.

\section{References}

1. Aronov DM, Bloch KC (2003) Assessing the relationship between the use of nonsteroidal antiinflammatory drugs and necrotizing fasciitis caused by group A Streptococcus. Medicine $82(4): 225-235$

2. Dinges M, Orwin P, Schlievert P (2000) Exotoxins of Staphylococcus aureus. Clin Microbiol Rev 13(1):16-34

3. Freeman HP, Oluwole SF, Ganepola GA, Dy E (1981) Necrotizing fasciitis. Am J Surg 142:377-383

4. Gorbach SL (1996) IDCP guidelines: necrotizing skin and soft tissue infections, part 1: necrotizing fasciitis. Infect Dis Clin Pract 5:406

5. Guiliano A, Lewis F, Hadley K, Blaisdell FW (1977) Bacteriology of necrotizing fasciitis. Am J Surg 134:52-57

6. Keynes G (ed) (1951) The apologie and treatise of Ambroise Pare. Falcon, London

7. Kupferwasser L, Yeaman MR, Nast CC et al (2003) Salicylic acid attenuates virulence in cardiovascular infections by targeting global regulatory pathways in Staphylococcus aureus. J Clin Invest 112(2):222-233

8. Lewis RT (1998) Soft tissue infections. World J Surg 22:146151

9. McHenry CR, Piotrowsk JJ, Petrinic D, Malongoni MA (1995) Determinants of mortality for necrotizing soft tissue infections. Ann Surg 221:558-563

10. Rea WJ, Wyrick WJ (1970) Necrotizing fasciitis. Ann Surg 172:957-964

11. Regev A, Weinberger M, Fishman M et al (1998) Necrotizing fasciitis caused by Staphylococcus Aureus. Eur J Clin Microbiol Infect Dis 17(2):101-103

12. Reiss S, Biddle NA (1994) The strept-A case. Newsweek June $20: 33$

13. Rouse TM, Malangoni MA, Schulte WJ (1982) Necrotizing fasciitis. A preventable Disaster. Surgery 765-770

14. Seal DV, Kingston D (1998) Streptococcal necrotizing fasciitis: development of an animal model to study its pathogenesis. Br J Exp Pathol 69:813-831

15. Stone HH, Martin JD (1972) Synergistic necrotizing cellulites. Ann Surg 175:702-711

16. Wilson B (1952) Necrotizing fasciitis. Am Surg 18:416-431

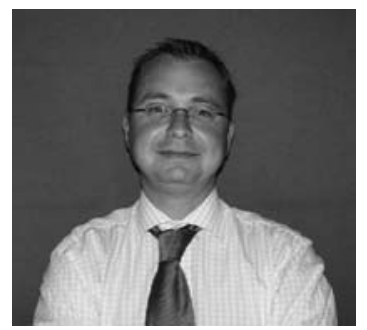

W. De Kerpel 